DOI: 10.12957/demetra.2017.22115

\title{
Alterações nutricionais e físico-químicas em repolho branco (Brassica oleracea) após o processamento mínimo e durante o armazenamento
}

\section{Nutritional and physicochemical changes of white cabbage (Brassica oleracea) after minimal processing and during storage}

\author{
Camila Faria Trivelato Batista? \\ Cassiano Oliveira da Silva' \\ Cláudia Maria Tomás Melo² \\ Erika Maria Marcondes Tassi ${ }^{1}$ \\ Grazieli Benedetti Pascoal ${ }^{1}$ \\ ' Universidade Federal de Uberlândia, Faculdade \\ de Medicina, Curso de Nutrição. Uberlândia-MG, \\ Brasil. \\ 2 Instituto Federal do Triângulo Mineiro, Curso de \\ Tecnologia em Alimentos. Uberlândia-MG, Brasil. \\ Correspondência / Correspondence \\ Grazieli Benedetti Pascoa \\ E-mail: grazi@famed.ufu.br
}

\section{Resumo}

Introdução: Hortaliças minimamente processadas (HMP) são alimentos que passam por etapas de pré-preparo, tornando-se totalmente aproveitáveis. O processamento mínimo causa injúrias no tecido vegetal, o que pode ocasionar perdas nutricionais. $\mathrm{O}$ repolho branco (Brassica oleracea) destaca-se entre as HMP por ser fonte de vitaminas, minerais e compostos bioativos. Objetivo: Avaliar alterações na qualidade nutricional e na atividade antioxidante de repolho branco após o processamento mínimo e durante o acondicionamento sob refrigeração. Metodologia: Foram analisados três lotes de repolho branco in natura e de minimamente processado, em triplicata e em 1, 7 e 14 dias após o armazenamento. A composição centesimal, o ácido ascórbico, os fenólicos totais e a atividade antioxidante foram determinados por métodos da Association of Official Analytical Chemists e do Instituto Adolfo Lutz. Foi utilizado o teste t não pareado para comparação dos tratamentos, e a vida de prateleira foi analisada pela análise de variância one-way, com teste de Tukey, e nível de significância de 5\%. Resultados e discussão: No t-1, os teores de umidade, proteínas, cinzas, carboidratos "disponíveis", ácido ascórbico, fenólicos totais, atividade antioxidante e o valor energético do repolho branco in natura e do minimamente processado apresentaram diferença $(\mathrm{p}<0,05)$, não observada entre si nos teores de lipídios e de fibras alimentares totais ( $p>0,05)$. No t-7, os teores de ácido ascórbico e atividade antioxidante reduziram significativamente, e o teor de fenólicos totais se manteve constante. Os teores de ácido ascórbico, atividade antioxidante e fenólico totais não apresentaram diferença significativa entre o t-7 e t-14. Conclusão: De uma 
maneira geral, a qualidade nutricional e a atividade antioxidante do repolho branco após o processamento mínimo e durante o acondicionamento sob refrigeração foram reduzidas.

Palavras-chave: Repolho. Processamento Mínimo dos Alimentos. Composição Centesimal. Atividade Antioxidante. Processos Físico-Químico. Qualidade dos Alimentos.

\section{Abstract}

Introduction: Fresh-cut vegetables are foods which are subjected to several preparation steps (sorting, peeling, cutting, washing, sanitation, centrifugation and packaging) which make them fully usable. Minimal processing causes injuries to vegetable tissues, leading to nutritional losses. White cabbage (Brassica olaracea) stands out among the other minimally processed vegetables as being a source of vitamins, minerals and bioactive compounds. Objective: To evaluate changes in the nutritional quality and antioxidant activity of white cabbage after minimal processing and during storage under refrigeration. Methodology: Samples of fresh and minimally processed white cabbage were purchased in three lots and analyzed at three different times, at 1, 7 and 14 days after storage. Proximate composition, ascorbic acid, total phenolics and antioxidant activity were determined by methods from the Association of Official Analytical Chemists and Instituto Adolfo Lutz. The unpaired t-test was performed to compare the data, and shelf-life was analyzed by one-way variance analysis, with Tukey's test and 5\% significance. Results and discussion: At $\mathrm{t}-1$, moisture, protein, ash, "available" carbohydrates, ascorbic acid, total phenolics, antioxidant activity and the energy value of fresh and minimally processed white cabbage showed differences $(p<0.05)$ while fat content and total dietary fiber did not show any difference $(p>0.05)$. At $t-7$, the content of ascorbic acid and antioxidant activity was reduced $(\mathrm{p}<0.05)$, and the total phenolic content remained constant. Ascorbic acid content, antioxidant activity and total phenolics did not show any difference $(\mathrm{p}>0.05)$ between t-7 and t-14. Conclusion: In general, the nutritional quality and antioxidant activity of white cabbage after minimal processing and during storage under refrigeration were reduced.

Keywords: Cabbage. Food Minimal Processing. Nutritional Composition. Antioxidant Activity. Physicochemical Processes. Food Quality. 


\section{Introdução}

As mudanças sociais, políticas e econômicas ocorridas nos últimos anos e a busca por um estilo de vida mais saudável têm aumentado a procura dos consumidores por alimentos frescos, prontos para o consumo e convenientes, principalmente as hortaliças e frutas. ${ }^{1-3}$ Nesse sentido, a indústria alimentícia vem procurando desenvolver novas tecnologias para o processamento de alimentos, as quais resultariam em produtos que atendessem às expectativas dos consumidores, lançando, assim, os alimentos minimamente processados para o mercado. ${ }^{3,4}$

Os alimentos minimamente processados (particularmente as hortaliças e frutas) são produtos que foram submetidos a operações de processamento mínimo, como, por exemplo: lavagem, sanitização, seleção, descascamento, corte, embalagem e armazenamento. É importante relatar que o processamento mínimo afeta o estado original dos alimentos, porém pode mantê-los próximo aos alimentos no seu estado in natura (estado original)., ${ }^{3,5-7}$

Os alimentos minimamente processados têm ganhado muito destaque pelos consumidores, pois são oferecidos em uma forma que permite o seu consumo imediato. Com isso, um mercado promissor tem surgido para mostrar e confirmar as novas tendências de consumo pela população., No Brasil, tais alimentos vêm obtendo uma participação crescente desde o início da década de 1990. E entre os mais comercializados e consumidos pela população brasileira estão os vegetais. Particularmente, o repolho branco minimamente processado se destaca, pois é uma das hortaliças mais populares do Brasil e é consumido como ingrediente em diversos pratos típicos da cultura alimentar brasileira. ${ }^{8}$

Muitos estudos vêm mostrando os benefícios de uma alimentação saudável, rica em hortaliças e frutas. Esses alimentos são muito importantes, já que podem diminuir o risco de desenvolvimento de algumas doenças crônicas não transmissíveis, como: câncer, doenças cardiovasculares, diabetes mellitus e obesidade. ${ }^{7,9}$ Do ponto de vista nutricional, o repolho branco apresenta muitos compostos, como: macronutrientes (carboidratos "disponíveis", fibras alimentares, proteínas e lipídios), micronutrientes (vitaminas C, B1, B2, E, K e minerais, principalmente cálcio e fósforo) e "compostos bioativos não nutrientes" (destaque para os glicosinolatos e compostos fenólicos). ${ }^{10}$ Os "compostos bioativos não nutrientes" e o ácido ascórbico (considerado um "composto bioativo nutriente") parecem ser os principais responsáveis pela alta capacidade antioxidante dos vegetais. ${ }^{7,8,11}$

Em geral, hortaliças e frutas se deterioram após a colheita devido às mudanças fisiológicas que podem espontaneamente acontecer. As alterações físico-químicas também são inevitáveis e mais intensas durante o processamento mínimo dos alimentos, quando comparados aos alimentos frescos (in natura). As operações do processamento mínimo danificam os tecidos vegetais, levando-os a injúrias e alterações metabólicas, e, com isso, a atividade das enzimas (principalmente a polifenol oxidase) e a taxa respiratória aumentam nos alimentos minimamente proces'sados. Então, as 
modificações bioquímicas decorrentes do processamento mínimo podem resultar em perda de nutrientes (vitaminas e açúcares) e de compostos bioativos (destaque para os compostos fenólicos). ${ }^{12-14}$

Portanto, é muito importante pesquisar se o processamento mínimo resulta significativamente na perda de macronutrientes (carboidratos "disponíveis", fibras alimentares, proteínas e lipídios), micronutrientes (vitaminas e minerais) e "compostos bioativos não nutrientes" (compostos fenólicos, carotenoides e glicosinolatos) ${ }^{7,10}$ Embora haja alguns estudos realizados para investigar as mudanças em diversos parâmetros de qualidade durante o armazenamento sob refrigeração de alimentos minimamente processados, a maioria deles tem focado principalmente na avaliação dos parâmetros físico-químicos (sólidos solúveis, $\mathrm{pH}$ e acidez) durante a vida de prateleira. ${ }^{15}$ Além disso, há ainda poucos estudos comparando as diferenças nutricionais entre vegetais in natura e vegetais minimamente processados., ${ }^{7,13,15,16}$

Até o momento, não foram encontradas pesquisas que avaliassem as alterações na composição centesimal, nos compostos bioativos e na atividade antioxidante em repolho branco após o processamento mínimo, com o objetivo de verificar o seu impacto na qualidade nutricional desse vegetal. Não foram encontradas, também, pesquisas que avaliassem a evolução e/ou o comportamento dos compostos fenólicos, do ácido ascórbico e da atividade antioxidante durante a vida de prateleira de repolho branco minimamente processado durante o armazenamento sob refrigeração.

Assim, o presente estudo objetivou investigar as alterações na composição centesimal (umidade, proteínas, lipídios, cinzas, carboidratos "disponíveis" e fibra alimentar), nos compostos fenólicos, no ácido ascórbico e na atividade antioxidante em repolho branco após o processamento mínimo. Além disso, avaliar o comportamento do ácido ascórbico, dos compostos fenólicos e da atividade antioxidante em repolho branco minimamente processado durante o armazenamento sob refrigeração.

\section{Metodologia}

Os repolhos brancos in natura e os minimamente processados foram adquiridos em uma indústria de processamento mínimo de vegetais, localizada em Uberlândia (MG), e distribuídos ao acaso. As amostras de repolho branco minimamente processado foram adquiridas do mesmo lote do repolho branco in natura, e o processamento mínimo foi feito no dia anterior à realização das análises. Durante o processamento mínimo, o repolho branco foi submetido às etapas de seleção, lavagem, classificação, corte (fatiamento), sanitização e centrifugação, sendo, imediatamente, armazenado em embalagem plástica, sob atmosfera passiva, e acondicionado sob refrigeração.

Foram analisados três lotes de repolho branco in natura e de minimamente processado, em três meses distintos. Foram adquiridos entre os meses de junho de 2013 e maio de 2014 e transportados 
em caixas isotérmicas para o Laboratório de Bromatologia e Microbiologia de Alimentos da Faculdade de Medicina da Universidade Federal de Uberlândia.

O repolho branco in natura foi utilizado como "alimento controle", sendo analisado apenas no primeiro dia de aquisição (t-1). As análises objetivaram investigar o efeito do processamento mínimo do repolho branco em parâmetros nutricionais (umidade, proteínas, lipídios, cinzas, fibras alimentares, carboidratos "disponíveis", ácido ascórbico e fenólicos totais) e na atividade antioxidante. As análises no t-1 consistiram em: 3 tomadas de ensaio (lotes 1, 2 e 3) x 2 tratamentos (in natura e minimamente processado) x 1 unidade amostral (cerca de 2 quilos) x 1 local x 3 análises (triplicata)..$^{15,17-19}$

Com relação ao armazenamento sob refrigeração, as amostras de repolho branco minimamente processado foram submetidas às análises de ácido ascórbico, fenólicos totais e atividade antioxidante durante 14 dias, sob refrigeração a $4^{\circ} \mathrm{C}$ e em três tempos distintos, a saber: t-1, t-7 e t-14. Assim, o delineamento experimental do estudo do armazenamento sob refrigeração consistiu em: 3 tomadas de ensaio (lotes 1, 2 e 3) x 1 tratamento (minimamente processado) x 1 unidade amostral (cerca de 2 quilos) x 1 local x 3 análises (triplicata)..$^{15,17-19}$

A composição centesimal (umidade, proteínas, cinzas, fibras alimentares e lipídios), o ácido ascórbico (composto bioativo "nutriente") e os fenólicos totais (compostos bioativos "não nutrientes") foram determinados por diversos métodos propostos pela Association of Official Analytical Chemists ${ }^{20}$ e pelo Instituto Adolfo Lutz. ${ }^{21}$ A umidade foi estabelecida pelo método de secagem em estufa a $65^{\circ} \mathrm{C}$ por 72 horas. Os lipídios foram analisados pelo método de Goldfish.$^{22}$ As cinzas foram determinadas pela quantificação do resíduo mineral fixo remanescente após incineração em mufla a $550^{\circ} \mathrm{C}$ por seis horas, segundo a metodologia 018/IV. ${ }^{21}$ As proteínas, por microKjeldahl, ${ }^{20}$ com a aplicação do fator 5,75 (fator de conversão para vegetais). ${ }^{23}$ Os teores de fibras alimentares totais foram determinados pelo método enzimático-gravimétrico. ${ }^{20} \mathrm{Os}$ carboidratos "disponíveis" por diferença foram calculados pela seguinte fórmula: \% CHO "disponíveis" = 100(umidade + proteínas + lipídios + cinzas + fibras alimentares), valores dados em porcentagem ( $\mathrm{g}$ "carboidratos disponíveis" por $100 \mathrm{~g}$ de alimento).${ }^{23}$ Os teores de ácido ascórbico foram estipulados pela metodologia 364/IV. ${ }^{21}$ Os fenólicos totais foram analisados pelo método de Folin-Cicolteau, ${ }^{24}$ utilizando o ácido gálico como padrão (mg de equivalentes de ácido gálico por $100 \mathrm{~g}$ de amostra). A atividade antioxidante foi determinada pela porcentagem (\%) de inibição de oxidação do radical livre 2,2-difenil-1-picril-hidrazil (DPPH) ${ }^{25}$

O valor energético total (VET) foi demonstrado em duas unidades: quilocalorias (kcal) e quilojoules $(\mathrm{kJ})$. As quilocalorias (kcal) foram estimadas pela multiplicação dos teores de carboidratos "disponíveis" (por diferença), proteínas e lipídios pelos valores 4, 4 e $9 \mathrm{kcal} / \mathrm{g}$, respectivamente. O VET em quilojoules $(\mathrm{kJ})$ foi determinado pela multiplicação do VET em quilocalorias (kcal) pelo fator 4,2. ${ }^{26,27}$ 
A umidade do repolho branco in natura e do minimamente processado foi estabelecida, e o extrato seco que sobrou foi utilizado para a determinação das análises da composição centesimal. O ácido ascórbico, os fenólicos totais e a atividade antioxidante foram determinados por amostras de repolho na base úmida. ${ }^{26,27}$

Os dados da composição centesimal (proteínas, lipídios, cinzas, fibras alimentares e carboidratos “disponíveis"), do valor energético e dos compostos bioativos (ácido ascórbico e fenólicos totais) do repolho in natura e do minimamente processado foram expressos na base úmida e na base seca. Os valores da atividade antioxidante e do ácido ascórbico da vida de prateleira sob refrigeração foram expressos em base úmida. O teor de fenólicos da vida de prateleira foi expresso em base seca.

Para comparação entre os tratamentos (in natura e minimamente processado), foi utilizado o teste t não pareado. Em adição, os resultados da vida de prateleira foram avaliados pela análise de variância one-way, com a aplicação do teste de Tukey. Foi considerado um nível de significância de $5 \%$, e a análise estatística foi feita com o auxílio do software SAEG versão 9.1.

\section{Resultados e discussão}

Com relação aos resultados obtidos das análises do repolho branco no momento de aquisição $(\mathrm{t}-1)$, foi possível observar que houve aumento significativo $(\mathrm{p}<0,05)$ no teor de umidade no repolho branco minimamente processado $(94,9 \% \pm 0,34 \%)$, quando comparado ao in natura $(92,8 \% \pm$ $0,85 \%)$. Corroborando o presente estudo, Verzeletti et al. ${ }^{28}$ encontraram aumento na umidade em amostras de cenoura minimamente processadas quando comparadas às in natura. Os danos físicos causados no tecido vegetal, durante processamento mínimo, podem provocar aceleração da taxa respiratória e da produção de etileno, o que contribui para o aumento de água no meio intracelular da hortaliça. ${ }^{29}$

Devido ao acréscimo do teor de umidade $(\mathrm{p}<0,05)$ do repolho minimamente processado quando comparado ao repolho in natura, os dados da composição centesimal (proteínas, lipídios, cinzas, carboidratos "disponíveis" e fibras alimentares), do valor energético, do ácido ascórbico e dos fenólicos totais foram expressos na base úmida e na base seca (Tabela 1). 
Tabela 1. Parâmetros nutricionais (\% ou mg/100 g) e valor energético (kcal/100 g e kJ/100 g) no repolho branco (Brassica olaracea) in natura e no minimamente processado no tempo inicial (t-1), expressos na base úmida e na base seca. ${ }^{1-2}$ Uberlândia-MG, 2014.

\begin{tabular}{|c|c|c|c|c|}
\hline \multirow[t]{2}{*}{$\begin{array}{l}\text { Parâmetros } \\
\text { Nutricionais }\end{array}$} & \multicolumn{2}{|c|}{$\begin{array}{l}\text { Repolho branco } \\
\text { in natura }\end{array}$} & \multicolumn{2}{|c|}{$\begin{array}{c}\text { Repolho branco } \\
\text { minimamente processado }\end{array}$} \\
\hline & Base úmida & Base seca & Base úmida & Base seca \\
\hline Umidade (\%) & $92,8 \pm 0,85^{\mathrm{a}}$ & - & $94,9 \pm 0,34^{b}$ & - \\
\hline Proteínas (\%) & $1,1 \pm 0,07^{\mathrm{a}}$ & $16,2 \pm 2,63^{\mathrm{A}}$ & $0,7 \pm 0,06^{\mathrm{b}}$ & $13,8 \pm 2,44^{\mathrm{A}}$ \\
\hline Lipídios (\%) & $0,1 \pm 0,00^{\mathrm{a}}$ & $1,1 \pm 0,16^{\mathrm{B}}$ & $0,1 \pm 0,00^{\mathrm{a}}$ & $1,5 \pm 0,10^{\mathrm{A}}$ \\
\hline Cinzas (\%) & $0,5 \pm 0,04^{\mathrm{a}}$ & $7,5 \pm 0,92^{\mathrm{A}}$ & $0,4 \pm 0,02^{\mathrm{b}}$ & $7,3 \pm 0,61^{\mathrm{A}}$ \\
\hline $\begin{array}{l}\text { Fibras alimentares } \\
(\%)\end{array}$ & $2,1 \pm 0,51^{a}$ & $29,5 \pm 4,78^{\mathrm{A}}$ & $2,0 \pm 0,46^{\mathrm{a}}$ & $38,7 \pm 8,21^{\mathrm{A}}$ \\
\hline $\begin{array}{l}\text { Carboidratos } \\
\text { “disponíveis" (\%) }\end{array}$ & $3,3 \pm 0,61^{\mathrm{a}}$ & $36,5 \pm 6,60^{\mathrm{A}}$ & $2,0 \pm 0,38^{b}$ & $39,0 \pm 7,63^{\mathrm{A}}$ \\
\hline $\begin{array}{l}\text { Valor energético } \\
(\mathrm{kcal} / 100 \mathrm{~g})\end{array}$ & $18,4 \pm 2,22^{\mathrm{a}}$ & $221,1 \pm 28,82^{\mathrm{A}}$ & $11,3 \pm 1,42^{\mathrm{b}}$ & $223,1 \pm 30,43^{\mathrm{A}}$ \\
\hline $\begin{array}{l}\text { Valor energético } \\
(\mathrm{kJ} / 100 \mathrm{~g})\end{array}$ & $77,4 \pm 9,33^{\mathrm{a}}$ & $928,6 \pm 121,06^{A}$ & $47,5 \pm 5,94^{\mathrm{b}}$ & $936,9 \pm 127,7^{\mathrm{A}}$ \\
\hline $\begin{array}{l}\text { Ácido ascórbico } \\
(\mathrm{mg} / 100 \mathrm{~g})\end{array}$ & $17,3 \pm 0,57^{\mathrm{a}}$ & $244,8 \pm 30,55^{\mathrm{A}}$ & $15,2 \pm 0,89^{b}$ & $304,8 \pm 33,46^{\mathrm{A}}$ \\
\hline $\begin{array}{l}\text { Fenólicos totais } \\
(\mathrm{mg} \text { EAG/100 g) }\end{array}$ & $27,9 \pm 0,36^{\mathrm{a}}$ & $387,3 \pm 5,02^{\mathrm{A}}$ & $18,8 \pm 0,26^{\mathrm{b}}$ & $367,6 \pm 5,00^{\mathrm{B}}$ \\
\hline
\end{tabular}

${ }^{1}$ Análises em três lotes $(n=3)$ em triplicata $(n=3) ;{ }^{2}$ Valores médios \pm desvio padrão; Letras minúsculas diferentes na mesma linha significam que houve diferença estatística $(\mathrm{p}<0,05$, teste t não pareado) na base úmida. Letras maiúsculas diferentes na mesma linha significam que houve diferença estatística ( $\mathrm{p}<0,05$, teste $\mathrm{t}$ não pareado) na base seca.

Com relação aos outros parâmetros da composição centesimal na base úmida, houve redução significativa nos teores de proteínas, cinzas e carboidratos "disponíveis" e da energia do repolho branco minimamente processado quando comparado ao repolho branco in natura $(\mathrm{p}<0,05)$. No entanto, os teores de lipídios e fibras alimentares no repolho branco in natura e no minimamente processado não apresentaram diferenças significativas entre si $(\mathrm{p}>0,05)$. Os resultados comparativos da composição centesimal (in natura x minimamente processado) demonstraram que a injúria 
provocada no tecido vegetal durante o processamento mínimo do repolho branco pode provocar perdas distintas de alguns componentes da composição centesimal.

Ainda na base úmida, foi possível observar redução significativa $(\mathrm{p}<0,05)$ nos teores de ácido ascórbico e compostos fenólicos no repolho branco após o processamento mínimo. A redução no teor do ácido ascórbico pode estar relacionada com a desorganização celular e a consequente oxidação do ácido ascórbico, devido à injúria tecidual no repolho branco durante o corte - uma das etapas do processamento mínimo. ${ }^{30}$ Tais resultados diferem dos apresentados por Maia et al., ${ }^{31}$ os quais não encontraram diferença significativa do teor de ácido ascórbico entre brócolis in natura e brócolis minimamente processado. Alarcón-Flores et al., ${ }^{7}$ ao estudarem o comportamento de hortaliças após o processamento mínimo, também notaram redução significativa no teor de fenólicos totais em cenoura e brócolis minimamente processados, quando comparados às mesmas hortaliças in natura. Essa redução pode ser justificada pela oxidação dos compostos fenólicos por oxirredutases (peroxidases e a polifenoloxidase), os quais estão relacionados diretamente com o escurecimento dos tecidos vegetais. ${ }^{32}$

Contudo, quando os dados são apresentados na base seca, o comportamento dos nutrientes após o processamento mínimo foi distinto, pois a umidade sofreu diferença significativa $(p<0,05)$ entre os tratamentos, ou seja, o teor de umidade do repolho minimamente processado foi maior $(\mathrm{p}<0,05)$ que o do in natura. Dessa forma, o teor de umidade do presente estudo pode ser considerado uma variável interferente, pois os dados sofreram modificações quando a retiramos da análise.

Os valores expressos em base seca são adequados para comparar alimentos com teores de umidade estatisticamente diferentes, então, nesses casos, a umidade é uma variável interferente. No presente estudo, os valores expressos em base seca demonstraram claramente que o comportamento dos nutrientes após o processamento mínimo (repolho in natura versus repolho minimamente processado) foi totalmente influenciado pelo teor de umidade do alimento. Na base seca, o teor de lipídios aumentou $(\mathrm{p}<0,05)$ e o teor de fenólicos diminuiu $(\mathrm{p}<0,05)$ no repolho minimamente processado quando comparado ao repolho in natura. Ao passo que as proteínas, as cinzas, as fibras alimentares, os carboidratos "disponíveis", a energia e o ácido ascórbico não sofreram alterações ( $p>0,05)$ após o processamento mínimo.

Analisar e comparar o valor nutricional através da base seca é uma ferramenta interessante para ver a influência da umidade sobre as variáveis. Vale ressaltar que os consumidores compram e ingerem alimentos com umidade, portanto os dados apresentados em base úmida mostraram como a matriz alimentar do repolho se comportou após o processamento mínimo, e os dados em base seca mostraram a influência da umidade no comportamento dos nutrientes após o processamento mínimo.

A atividade antioxidante do presente estudo foi de $61,1 \%( \pm 1,20 \%)$ para o repolho in natura e $52,0 \%( \pm 2,10 \%)$ para o repolho minimamente processado, havendo decréscimo significativo 
$(\mathrm{p}<0,05)$ dessa atividade após o processamento mínimo. Os resultados de Gil et al. ${ }^{33}$ corroboraram a presente pesquisa e verificaram que o espinafre in natura apresentou redução significativa da capacidade antioxidante após o processamento mínimo. A higienização e o fatiamento das hortaliças, durante o processamento mínimo, desarranjam a estrutura do tecido vegetal e expõem os nutrientes à fação de determinadas enzimas presentes naturalmente nos vegetais, podendo reduzir a capacidade antioxidante. ${ }^{34}$

Com relação aos resultados obtidos ao longo do armazenamento sob refrigeração (t-1, t-7, t-14), foi possível observar redução significativa $(\mathrm{p}<0,05)$ no teor de ácido ascórbico e atividade antioxidante do repolho branco minimamente processado, após sete dias de armazenamento sob refrigeração. Não houve diferença $(\mathrm{p}<0,05)$ no teor de ácido ascórbico e atividade antioxidante entre o sétimo e décimo quarto dia de armazenamento sob refrigeração (Tabela 2).

Tabela 2. Ácido ascórbico (mg/100g), atividade antioxidante (\%), expressos na base úmida, e fenólicos totais (mg EAG/100g), expressos na base seca, no repolho branco (Brassicaolaracea) minimamente processado durante o acondicionamento sob refrigeração $(\mathrm{t}-1, \mathrm{t}-7, \mathrm{t}-14){ }^{1,2}$ Uberlândia-MG, 2014.

\begin{tabular}{lccc}
\hline & Repolho branco & Repolho branco & Repolho branco \\
Variáveis & MP & MP & MP \\
& $(\mathrm{t}-1)$ & $(\mathrm{t}-7)$ & $(\mathrm{t}-14)$ \\
Ácido ascórbico $(\mathrm{mg} / 100 \mathrm{~g})$ & $15,2 \pm 0,84^{\mathrm{a}}$ & $13,6 \pm 0,69^{\mathrm{b}}$ & $12,8 \pm 1,47^{\mathrm{b}}$ \\
Fenólicos totais $(\mathrm{mg}$ EAG/100 g) & $367,6 \pm 4,72^{\mathrm{a}}$ & $363,8 \pm 4,67^{\mathrm{a}}$ & $363,2 \pm 5,49^{\mathrm{a}}$ \\
Atividade antioxidante $(\%)$ & $52,1 \pm 2,00^{\mathrm{a}}$ & $42,0 \pm 1,61^{\mathrm{b}}$ & $40,1 \pm 1,43^{\mathrm{b}}$ \\
\hline
\end{tabular}

${ }^{1}$ Análises em três lotes $(n=3)$ em triplicata $(n=3)$; ${ }^{2}$ Valores médios \pm desvio padrão; Letras minúsculas diferentes na mesma linha significam que houve diferença estatística $(\mathrm{p}<0,05$, análise de variância one-way, Teste de Tukey). $\mathrm{T}-1=1$ dia de armazenamento; $\mathrm{t}-7=7$ dias de armazenamento; $\mathrm{t}-14=14$ dias de armazenamento.

Observando a Tabela 2, notou-se que a atividade antioxidante e o ácido ascórbico diminuíram ao longo do acondicionamento sob refrigeração. Então, pode-se inferir que essa redução da atividade antioxidante tenha se dado por causa do ácido ascórbico. Para certificar-se de que as variáveis ácido ascórbico e atividade antioxidante tivessem uma associação, foi feita uma correlação de Pearson (Figura 1) e constatou-se que o ácido ascórbico e a atividade antioxidante tiveram uma forte e positiva correlação entre si $(r=+0,98)$, ou seja, à medida que o teor ácido ascórbico decaía, a atividade antioxidante também acompanhava essa tendência ao longo da vida de prateleira. 


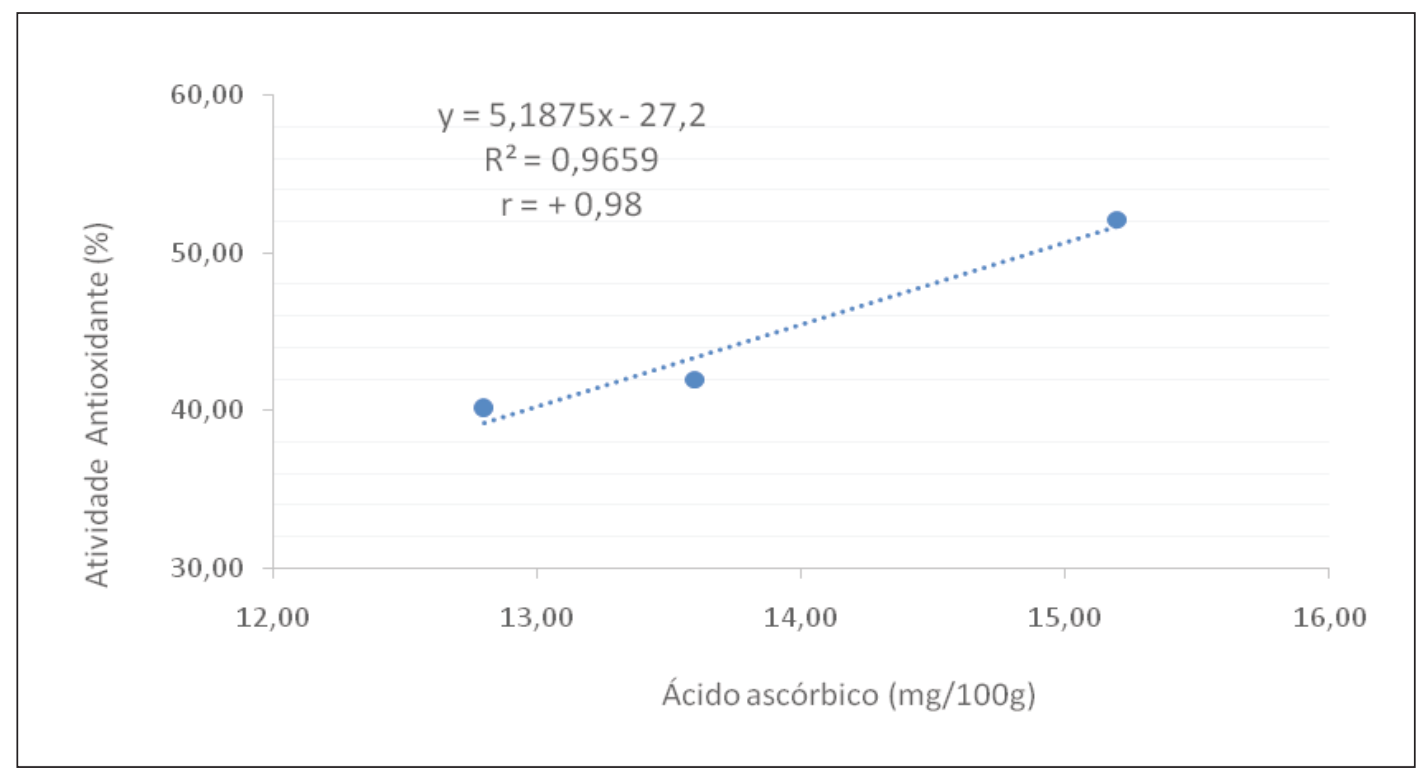

Figura 1. Correlação de Pearson entre o teor de ácido ascórbico $(\mathrm{mg} / 100 \mathrm{~g})$ e a atividade antioxidante (\%) durante o acondicionamento sob refrigeração no repolho branco (Brassica olaracea) minimamente processado durante o acondicionamento sob refrigeração (t-1, t-7, t-14). ${ }^{1,2}$ Uberlândia-MG, 2014.

Ao longo do armazenamento de produtos hortícolas, há a tendência da redução do teor de ácido ascórbico, principalmente devido à ação da enzima ácido ascórbico oxidase (ascorbinase) ou de outras enzimas oxidantes (por exemplo, as peroxidases). ${ }^{35}$ Os resultados do presente trabalho corroboraram o de Alves et al., ${ }^{30}$ que verificaram redução significativa do ácido ascórbico em salada mista (chuchu, cenoura, mandioquinha e abóbora) minimamente processada após oito dias de armazenamento sob refrigeração. Hussein et al., ${ }^{36} \mathrm{em}$ estudo realizado com brócolis in natura e brócolis minimamente processado, também observaram redução significativa no teor de ácido ascórbico durante dez dias de armazenamento sob refrigeração.

O comportamento da atividade antioxidante do presente estudo difere dos encontrados por Russo et al., ${ }^{37}$ que, ao analisarem abóbora minimamente processada, observaram aumento da atividade antioxidante até o nono dia de armazenamento e redução considerável a partir do 12으 dia de armazenamento sob refrigeração. 
O teor de fenólicos totais no repolho branco minimamente processado não apresentou diferença significativa $(\mathrm{p}>0,05)$ durante os três tempos analisados da vida de prateleira (t-1, t-7, t-14), com valor médio de 364,9 mgEAG/100 g na base seca.

Existe forte divergência entre os autores sobre a correlação entre o teor de fenólicos e a atividade antioxidante. Alguns trabalhos têm demonstrado que quanto maior o teor de fenólicos em um alimento, maior seria a sua atividade antioxidante, como o realizado por Kaur e Kapoor, ${ }^{38}$ que encontraram relação significativa entre os fenólicos totais e a atividade antioxidante em vegetais. ${ }^{39,40}$ Contudo, outras pesquisas, como a realizada por Ismail et al., ${ }^{41}$ não têm evidenciado esta correlação, pois defendem que a atividade antioxidante depende da composição físico-química do alimento como um todo, não sendo baseada, portanto, apenas pelo seu teor de compostos fenólicos. ${ }^{42,43}$

\section{Conclusão}

De uma maneira geral, a qualidade nutricional e a atividade antioxidante do repolho branco minimamente processado não foram totalmente preservadas, quando comparadas ao repolho branco in natura. Então, concluiu-se que o repolho in natura apresentou melhor qualidade nutricional em relação ao repolho minimamente processado. Contudo, o minimamente processado vai ao encontro das expectativas e necessidades de outros tipos de consumidores contemporâneos, os quais buscam cada vez mais conveniência e/ou praticidade nos produtos alimentícios.

Como conclusão, novos estudos científicos devem ser realizados com relação às mudanças nutricionais e físico-químicas após o processamento mínimo de vegetais, particularmente o repolho branco. Em adição, pesquisas envolvendo a investigação das atividades enzimáticas e modificações fisiológicas pós-colheita durante o armazenamento do repolho minimamente processado seriam de grande valia e trariam dados mais aprofundados sobre o comportamento físico-químico de vegetais após o processamento mínimo.

\section{Colaboradores}

Os autores participaram de todas as etapas, desde a concepção do estudo até a revisão da versão final do artigo.

Conflito de Interesses: Os autores declaram não haver conflito de interesses. 


\section{Referências}

1. Cantwell M, Suslow TV. Postharvest handling systems: minimally processed fruits and vegetables. In: Kader AA, editors. Postharvest technology of horticultural crops. Davis: University California; Division of Horticultural and Natural Resources; 2002. p. 445-463.

2. Pilon L. Estabelecimento de vida útil da vida útil de hortaliças minimamente processadas sob atmosfera modificada e refrigeração [dissertação]. [Piracicaba]: Escola Superior de Agricultura Luiz de Queiroz Piracicaba, Universidade de São Paulo; 2003.

3. Santosa J, Herrerob M, Mendiolab JA, Oliva-telesc MT, Ibáñezb E, Delerue-matosc C, et al. Fresh-cut aromatic herbs: nutritional quality stability during shelf life. LWT - Food Science and Technology 2014; 59(1):101-107.

4. Cenci SA. Processamento mínimo de frutas e hortaliças: tecnologia, qualidade e sistemas de embalagem. Rio de Janeiro: Embrapa Agroindústria de Alimentos; 2011. 144 p.

5. Procedure for vegetables preserved by combined methods. In: Barbosa-Cánovas G, FernándezMolina JJ, Alzamora SM, Tapia MS, López-Malo A, Chanes JW. Handling and preservation of fruits and vegetables by combined methods for rural areas. Rome: FAO; 2003. Technical Manual FAO Agricultural Services Bulletin, 149.

6. Martín-Belloso O, Soliva-Fortuny R, Oms-Oliu G. Fresh-cut fruits. In: Hui YH. Handbook of food products manufacturing. New Jersey: John Wiley e Sons; 2007. p. 879-900.

7. Alarcón-Flores MI, Romero-González R, Vidal JLM, González FJE, Frenich AG. Monitoring of phytochemicals in fresh and fresh-cut vegetables: a comparison. Food Chemistry 2014; 142(1):392-399.

8. Moretti CL. Manual de processamento mínimo de frutas e hortaliças. Brasília: Embrapa Hortaliças; 2007. $531 \mathrm{p}$.

9. Jaime PC, Machado FMS, Westphal MF, Monteiro CA. Educação nutricional e consumo de frutas e hortaliças: ensaio comunitário controlado. Rev Saúde Pública 2007; 41(1):154-157.

10. Bastos DHM, Rogero MM, Arêas JAG. Mecanismos de ação de compostos bioativos dos alimentos no contexto de processos inflamatórios relacionados à obesidade. Arq Bras Endocrinol Metab. 2009; 53(1):53-55.

11. Rice-Evans CA, Miller NJ, Paganga G. Structure antioxidant activity relationship of flavonoids and phenolic acids. Free Radic Biol Med. 1996; 20(7):933-956.

12. Pineli LLO, Moretti CL, Almeida GC, Nascimento ABG, Onuki ACA. Associação de atmosfera modificada e antioxidantes reduz o escurecimento de batatas "Ágata" minimamente processadas. Hortic Bras. 2005; 23(4):993-999.

13. Gil MI, Aquayo E, Kader AA. Quality changes and nutriente retention in fresh-cut versus whole fruits during storange. J Agric Food Chem. 2006; 54(12):4284-4296.

14. Sasaki FF, Aguila JSD, Gallo CR, Ortega EMM, Jacomino AP, Kluge RA. Alterações fisiológicas, qualitativas e microbiológicas durante o armazenamento de abóbora minimamente processada em diferentes tipos de corte. Hortic Bras. 2006; 24(2):170-174. 
15. Ferreira TA, Silva CO, Pascoal GB. Análise físico-química em repolho branco (BrassicaOlaracea) minimamente processado durante o acondicionamento sob refrigeração. Linkania 2014; 8(1):59-72.

16. Mishra BB, Gautam S, Sharma A. Browning of fresh-cut eggplant: impact of cutting and storage. Postharvest Biology and Technology 2012; 67(1):44-51.

17. Groppo VD, Spoto MHF, Gallo CR, Sarmento SBS. Efeito do cloreto de cálcio e da película de alginato de sódio na conservação de laranja 'Pera' minimamente processada. Ciênc Tecnol Aliment. 2009; 29(1):107-113.

18. De-Souza EC, Vilas-Boas EVB, Vilas-Boas BM, Rodrigues LJ, De-Paula NRF. Qualidade e vida útil de pequi minimamente processado armazenado sob atmosfera modificada. Ciênc Agrotec. 2007; 31(6):1811-1817.

19. Oliveira LE, Silva CO, Pascoal GB. Comparação entre a composição nutricional dos rótulos e as análises laboratoriais de queijos minas frescal (tradicional e light). Rev Inst Laticínios Cândido Tostes 2014; 69(4):280-288.

20. Association of Official Analytical Chemists. Official methods of analysis of the AOAC International.19 ed. Washington: AOAC; 2012.

21. Instituto Adolfo Lutz. Normas analíticas do Instituto Adolfo Lutz: métodos físico-químicos para análise de alimentos. São Paulo: Instituto Adolfo Lutz; 2008. 1020 p.

22. Cecchi HM. Fundamentos teóricos e práticos em análise de alimentos. 2 ed. Campinas, SP: Editora Unicamp; 2003. 208 p.

23. Brasil. Resolução - RDC n 360, de 23 de dezembro de 2003. Regulamento Técnico sobre Rotulagem de Alimentos Embalados. Diário Oficial da União 26 dez. 2003.

24. Singleton VL, Rossi JR. Calorimetry of total phenolics with phosphomolybdic-phosphotungstic acid reagents. Am J Enol Vitic. 1965; 16(3):144-158.

25. Brand-Wilians W, Cuvelier ME, Berset C. Use of a free radical method to evaluate antioxidant activity. Food Science and Technology 1995; 28(1):25-30.

26. Da Paz JG, Pacheco P, Da Silva CO, Pascoal GB. Análise da composição nutricional e de parâmetros físico-químicos do pequi (caryocar brasiliense camb) in natura. Linkania 2014; 1(8):73-86.

27. Pacheco P, Paz JG, Silva CO, Pascoal GB. Composição centesimal, compostos bioativos e parâmetros físico-químicos do jenipapo (genipa americana L.) in natura. Demetra 2014; 9(4):1041-1054.

28. Verzeletti A, Fontana RC, Sandri IG. Avaliação da vida de prateleira de cenouras minimamente processadas. Alim Nutr. 2010; 21(1):87-92.

29. Varoquaux P, Wiley RC. Biological and biochemical changes in minimally processed refrigerated fruits and vegetables, In: Wiley C, editor. Minimally processed refrigerated fruits e vegetables. New York: Chapman e Hall; 1994. p. 226-268.

30. Alves JA, Vilas Boas EVB, Vilas Boas BM, Souza EC. Qualidade de produto minimamente processado à base de abóbora, cenoura, chuchu e mandioquinha-salsa. Ciênc Tecnol Aliment. 2010; 30(3):625-634.

31. Maia GEG, Pasqui SC, Lima AS, Campos FM. Determinação dos teores de vitamina C em hortaliças minimamente processadas. Alim Nutr. 2008; 19(3):329-335. 
32. Vermerris W, Nicholson R. Phenolic compound biochemistry. Dordrecht: Springer Netherlands; 2006. 276 p.

33. Gil MI, Ferreres F, Tomás-Barberán FA. Effect of postharvest storage and processing on the antioxidant constituents (flavonoids and vitamin C) of fresh-cut spinach. J Agric Food Chem. 1999; 47(6):2213-2217.

34. Campos FM, Martino HSD, Sabarense CM, Pinheiro-Sant'ana HM. Estabilidade de compostos antioxidantes em hortaliças processadas. Alim Nutr. 2008; 19(4):481-490.

35. Chitarra MIF, Chitarra AB. Pós-colheita de frutas e hortaliças: fisiologia e manuseio. Lavras, MG: UFLA; 2005. 785 p.

36. Hussein A, Odumeru JA, Ayanbadejo T, Faulkner H, Mcnab WB, Hager H, et al. Effects of processing and packaging on vitamin $C$ and $\beta$-caroteno content of ready-to-use (RTU) vegetables. Food Research International 2000; 33(1):131-136.

37. Russo VC, Daiuto ER, Santos BL, Lozano MG, Vieites RL, Vieira MRS. Qualidade de abóbora minimamente processada armazenada em atmosfera modificada ativa. Semina: Ciências Agrárias 2012; 33(3):1071-1084.

38. Kaur C, Kapoor HC. Anti-oxidant activity and total phenolic content of some Asian vegetables. Int. J. Food Sci. Technol. 2002; 37(2):153-161.

39. Melo EA, Maciel MIS, Lima VLAG, Leal FLL, Caetano ACS, Nascimento RJ. Capacidade antioxidante de hortaliças usualmente consumidas. Ciênc Tecnol Aliment. 2006; 26(3):639-644.

40. Velioglu YS, Mazza G, Gao L, Oomah BD. Antioxidant activity and total phenolics in selected fruits, vegetables and grain products. J. Agric. Food Chem. 1998; 46(1):4113-4117.

41. Ismail A, Marjan ZM, Foong CW. Total antioxidant activity and phenolic content in selected vegetables. Food Chem. 2004; 87(4):581-586.

42. Heinonen M, Lehtonen PJ, Hopia A. Antioxidative activity of berry and fruit wines and liquor. J Agric Food Chem. 1998; 48(1):25-31.

43. Kahkonen MP, Hopia AI, Vuorela HJ, Rauha JP, Pihlaja K, Kujala TS, et al. Antioxidant activity of plant extracts containing phenolic compounds. J Agric Food Chem. 1999; 47(10):3954-3962.

Recebido: $24 / 3 / 2016$

Revisado: 21/9/2016

Aceito: 26/10/2016 